\title{
Polymorphism Investigation of (4-(4'-Octylobiphenyl)carboxylane) 4-(2-Methylobuthyl) Phenol Liquid Crystal Having Blue Phase
}

\author{
G. LEWIŃSKA ${ }^{a, b}$ AND W. OTOWSKI ${ }^{a, *}$ \\ ${ }^{a}$ Institute of Physics, Cracow University of Technology, Podchorążych 1, 30-084 Cracow, Poland \\ ${ }^{b}$ The Henryk Niewodniczański Institute of Nuclear Physics of the Polish Academy of Sciences, Cracow, Poland \\ (4-(4'-octylobiphenyl)carboxylane) 4-(2-methylobuthyl) phenol, the substance showing complex polymor- \\ phism, has been investigated using the calorimetric, microscopic and X-ray methods. This substance exhibited \\ polymorphism during heating and cooling: a few smectic phases, a cholesteric phase and a blue phase as well. \\ However, the substance polymorphism depends on the rate of heat flow. Existing of the blue phase has been \\ confirmed by polarizing microscopic observations done at several temperature rates.
}

PACS numbers: 61.30.Pq, 61.30.Eb, 64.70.M-, 42.70.Df

\section{Introduction}

Liquid crystals are structures built up of anisotropic molecules. However, the open question is how the one anisotropic molecule as a main structural element may set in order giving a phase or sequence of different phases. Especially the so-called blue phase (BP) arrangement is the most interesting property. Therefore the investigation of the substance, having a simple chemical structure and different phase sequence including the blue phase, seems to be interesting.

History of the blue phase is as long as history of liquid crystals. For the first time the blue phase was reported in 1888 as briefly blue colour of substance appearing just before clearing point. It appears in narrow temperature regions (about $1{ }^{\circ} \mathrm{C}$ ). However in 2005 , researchers from the University of Cambridge reported their discovery of a class of blue-phase liquid crystals that remain stable over a wide temperature range (thermodynamically stable for $16-60^{\circ} \mathrm{C}$ ) [1] and which would be used to switch the colour of the reflected light by applying an electric field to the material, and that this could eventually be used to produce three-colour (red, green, and blue) pixels for full-colour displays [2], the blue phase becomes the very interesting mesophase. Currently (in 2007) Samsung presented the first LCD "Blue Phase" display which does not require anisotropic alignment layers (e.g., rubbed polyimide) and thus simplified the LCD manufacturing process. Except that the blue phase is a curiosity of nature, it proves to be quite an interesting system for studying the properties of oriented molecule systems.

The blue phase (correctly speaking: phases) occurs ex-

* corresponding author; e-mail: w_otowski@wp.pl tremely rarely between cholesteric phase and isotropic liquid. There are three stable blue phases: BPI, BPII and BPIII called blue fog. Blue phases I and II show cubic symmetry. For BPI it is body center cubic symmetry, elementary cell size changes with temperature. BPII shows simple cubic symmetry and there is no temperature change in elementary cell size. BPIII is almost amorphic (chiral positional ordering short-range).

The blue phase is a state with unusual properties. Order parameter exhibits three-dimensional orientational ordering with periods of up to $500 \mathrm{~nm}$. Therefore, the blue phase is not detected by X-rays - shows no peaks in X-ray diffraction. Sometimes one may observe a blue colour of substance in macro scale or even a mosaic of colour.

It is shown [3] that the blue phases are special cases when a "double twist" structure fill up large volumes. The double twist means structure in which the director twists simultaneously about two independent directions (Fig. 1).

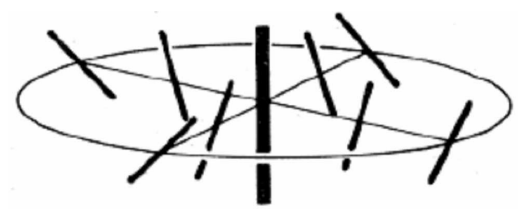

Fig. 1. "Double twist" structure of the director. The directors rotate when moving along both the pitch axis and the direction perpendicular to it, and accomplish a rotation of $90^{\circ}$ across the diameter.

This double twist structure is more stable than the single one (i.e., the normal helical structure of chiral nematics) only up to a certain radius of the double twist cylinder. It means that the double twist structure occurs 
only rarely. A large structure can be composed from these double twist cylinders, however at the points where the cylinders are in contact, the defects occur — disclination (as illustrated in Fig. 2) [4].

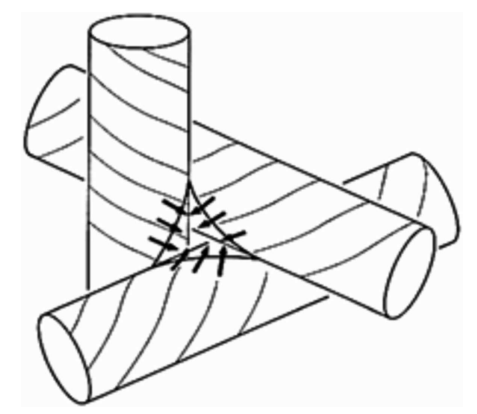

Fig. 2. Structure of BP. Intersection of three double twist cylinders; arrows show declinations.

\section{Material}

The substance (Fig. 3) under study was synthesized in the Institute of Chemistry, the Military University of Technology in Warsaw. It was preliminarily studied there and gave reasons to suspect of wide variety mesophases.

\section{Results}

\subsection{Calorimetry}

Main method for temperature research was differential scanning calorimetry (DSC). The enthalpy changes connected with phase transition are visible as curves peaks. Several series of measurements with different rates of heating and cooling $\left(5^{\circ} \mathrm{C} / \mathrm{min}, 30^{\circ} \mathrm{C} / \mathrm{min}\right)$ were performed. Undesired alteration of DSC baseline was an aparatus artifact. Howerver, this effect did not influence peak positions (which we were interested in). Moreover, the peak positions were measured precisely with a good accuracy of $\pm 0.1^{\circ} \mathrm{C}$.

DSC experiment detected a few phases. The range of existing liquid crystal phases is impressive, almost $100^{\circ} \mathrm{C}$. We propose the following phase diagram:

- on heating:

Cr $49.2^{\circ} \mathrm{C}$ M1 $66.5^{\circ} \mathrm{C}$ M2 $68.9^{\circ} \mathrm{C}$ M3 $72.5^{\circ} \mathrm{C}$ M4 $139.5^{\circ} \mathrm{C}$ M5 $143.2^{\circ} \mathrm{C}$ I

- on cooling:

I $141.5^{\circ} \mathrm{C}$ M5 $137.7^{\circ} \mathrm{C}$ M4 $70.6^{\circ} \mathrm{C}$ M3 $67.8^{\circ} \mathrm{C}$ M2 $64.7^{\circ} \mathrm{C}$ M1 $43.0^{\circ} \mathrm{C} \mathrm{Cr}$.

Figure 4 presents DSC results and clearly shows the existence of five phases and that the transitions between them are of the first order, as evidenced by the existence of latent heats (the spikes on the graph). The first peak represents phase transition between crystal state and mesophase, the last one is phase transition between mesophase and isotropic liquid. It is supposed that there is some type of smectic phases. There is a small shift between heating and cooling peaks.

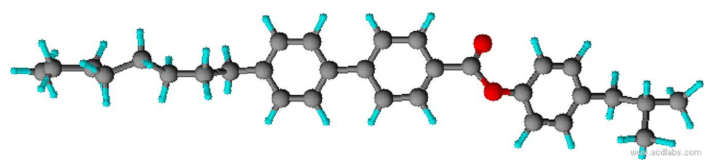

Fig. 3. Model of (4-(4'-octylobiphenyl)carboxylane) 4-(2-methylobuthyl) phenol molecule [5].

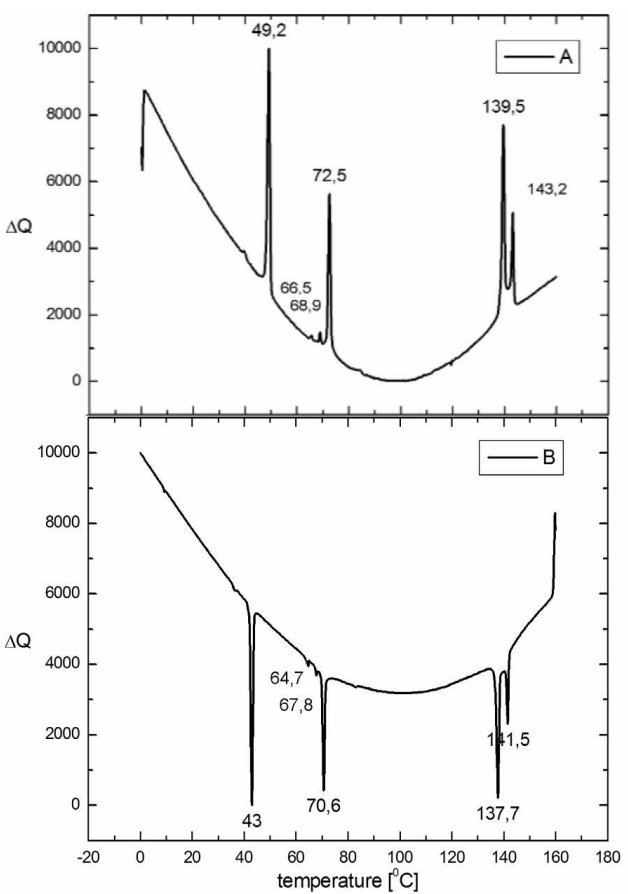

Fig. 4. DSC results for temperature rate $5{ }^{\circ} \mathrm{C} / \mathrm{min}$ : (A) heating, (B) cooling.

\subsection{Microscopy}

The image of a thin layer of liquid crystal observed under an optical microscope between crossed polarizers is called texture. Often, these textures are distinctive (typical) for mesophases and may be used to identify liquid crystal (LC) type.

Microscope observation was made with the following temperature rates: $5^{\circ} \mathrm{C} / \mathrm{min}, 10^{\circ} \mathrm{C} / \mathrm{min}$, and $30^{\circ} \mathrm{C} / \mathrm{min}$. All DSC-observed phase transitions were confirmed. However, we noticed one more transition. Among mesophase M5 and isotropic liquid we recognized a new phase, with texture typical for the blue phase (Figs. 5 and 6). Therefore, we may suspect that M5 phase is a cholesteric one (BP phase is observed between cholesteric phase and the clearing point). 


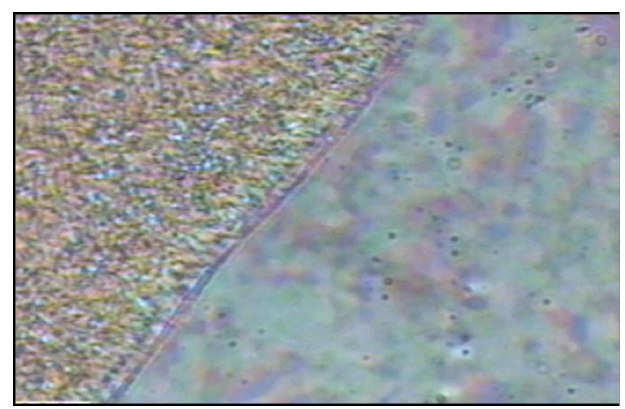

Fig. 5. Phase transition; cholesteric liquid crystal phase (left side) and the blue phase (right side), temperature $141{ }^{\circ} \mathrm{C}$ with $0.2{ }^{\circ} \mathrm{C} / \mathrm{min}$ cooling rate.

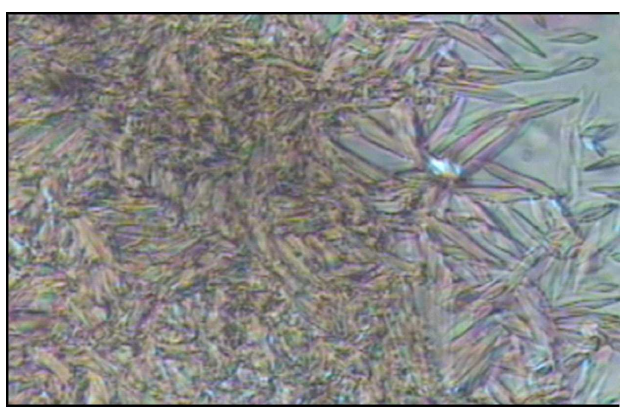

Fig. 6. Blue phase (right side), cholesteric liquid crystal (left side), and smectic A "needles" (fan-shaped texture). "Double" phase transition obtained on cooling with $0.2{ }^{\circ} \mathrm{C} / \mathrm{min}$ rate, at temperature $141^{\circ} \mathrm{C}$.

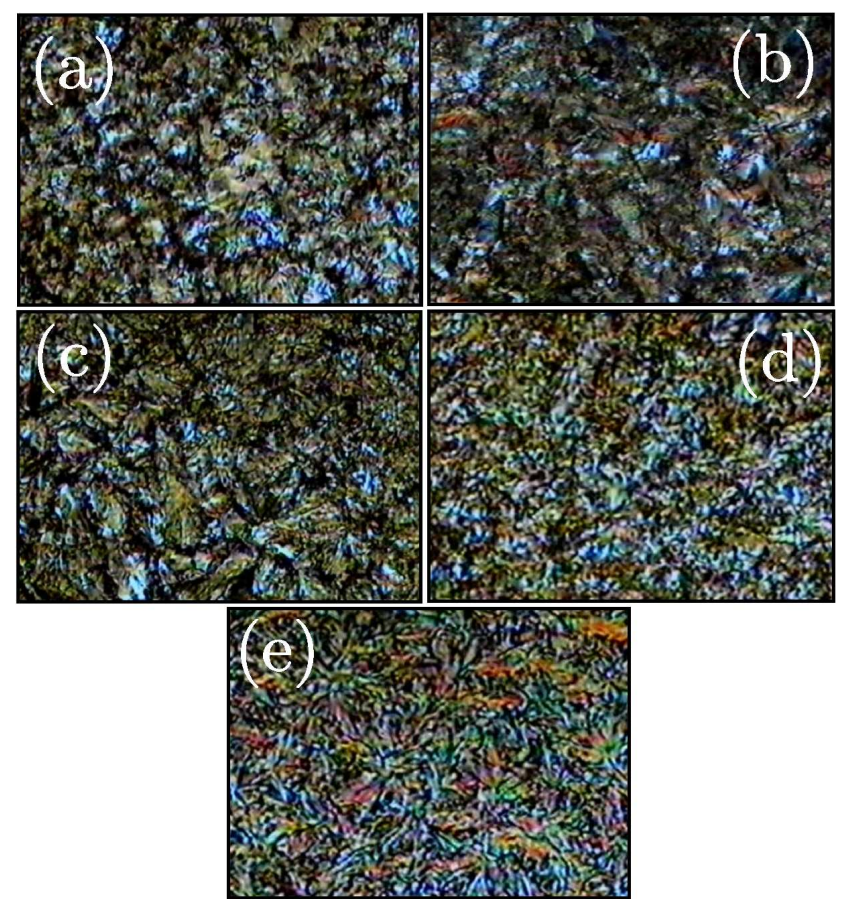

Fig. 7. Mesophases sequence as seen via texture images. (a) M1 - mosaic texture, (b) M2 - fun shaped texture, (c) M3 - funshaped and fingerprint texture, (d) M4 - focal conic and fun shaped texture, (e) M5 - cholesteric liquid crystal texture.
In Fig. 4 there is no peak for the blue phase. Measurements done with lower temperature changes did not show this phase, again. It may be because of small enthalpy changes of this kind of the phase transition. Therefore, we performed polarizing microscopic dynamic measurements of Ch-BP transition, whose results are presented in Table.

TABLE

Blue phase transition dynamics.

\begin{tabular}{c|c|c}
\hline \hline $\begin{array}{c}\text { Temperature } \\
\text { rate }\left[{ }^{\circ} \mathrm{C} / \mathrm{min}\right]\end{array}$ & $\begin{array}{c}\text { Heating } \\
\text { existing regions }\left[{ }^{\circ} \mathrm{C}\right]\end{array}$ & $\begin{array}{c}\text { Cooling } \\
\text { existing regions }\left[{ }^{\circ} \mathrm{C}\right]\end{array}$ \\
\hline 0.2 & $142.8-143.8$ & $143.7-142.8$ \\
5 & $143.2-143.9$ & $143.6-140.2$ \\
10 & $143.1-144.1$ & $143.1-139.8$
\end{tabular}

We have postulated the following identification of other mesophases: M4 mesophase (focal conic and fun-shaped texture) as SmA, M3 mesophase (fun-shaped, fingerprint texture) as $\mathrm{SmC}$, M2 mesophase (fun-shaped texture) as SmI and M1 mesophase (mosaic texture) as SmG. In Fig. 7 mesophases sequence (as seen via texture images) is presented.

\subsection{X-rays pattern - preliminary results}

The X-ray studies were performed on X'Perrt PRO (PANalytical) diffractometer using the $\mathrm{Cu} K_{\alpha}$ radiation $(\lambda=1.54178 \AA)$ and a graphite monochromator. The sample was placed in a nickel-plated copper sample holder of dimensions $18 \times 9 \times 0.2 \mathrm{~mm}^{3}$. The temperature of the sample was stabilized (accuracy $\pm 0.1^{\circ} \mathrm{C}$ ) with the continuous flow cryostat supplied by Anton Paar Co. The sample was not oriented. Prior to the temperature measurements the sample was melted, next cooled to room temperature with the rate of $10^{\circ} \mathrm{C} / \mathrm{min}$, and next left for $24 \mathrm{~h}$ at this temperature. After this relaxing time the sample was cooled down to liquid $\mathrm{N}_{2}$ temperature with rate $10^{\circ} \mathrm{C} / \mathrm{min}$, and finally left for $12 \mathrm{~h}$. The patterns were obtained at rising temperature. After each heating stage the sample was allowed to equilibrate for about $10 \min [5]$.

Figure 8 shows X-ray patterns as a function of temperature. Up to $130^{\circ} \mathrm{C}$ a few reflections were detected on each diffraction line corresponding to a layered structure of smectic phases. One may see that the first transition (indicated by first bottom arrow) was pointed out by vanishing $8.5^{\circ} \mathrm{C}$ and $11.75^{\circ} \mathrm{C}$ reflections. Moreover, $15.0^{\circ} \mathrm{C}$ and $15.7^{\circ} \mathrm{C}$ reflections show reverse intensity before and after transition point. The second transition (indicated by second arrow) was pointed out by vanishing $12.5^{\circ} \mathrm{C}$ and $15.75^{\circ} \mathrm{C}$ reflections. The third transition (indicated by third arrow) was pointed out by vanishing $3.5^{\circ} \mathrm{C}, 5.0^{\circ} \mathrm{C}, 7.75^{\circ} \mathrm{C}$, and $15^{\circ} \mathrm{C}$ reflections. The fourth transition (indicated by fourth arrow) was pointed out by vanishing $9.0^{\circ} \mathrm{C}$ reflection. Only two reflections $\left(3^{\circ} \mathrm{C}\right.$ and $6{ }^{\circ} \mathrm{C}$ ) remain. The fifth transition (indicated by fifth arrow) was pointed out by vanishing all reflections. The 


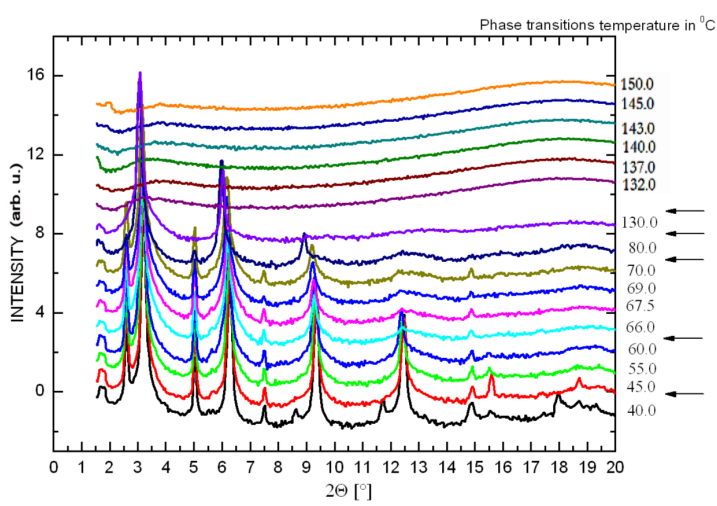

Fig. 8. The X-ray pattern vs. temperature (arrows pointed out the phase transition points).

sixth transition (form cholesteric phase to the blue one) is not detected by X-rays (see Sect. 1).

\section{Conclusions}

For (4-(4'-octylobiphenyl)carboxylane) 4-(2-methylobuthyl) phenol we observe four smectic phases, cholesteric liquid crystal and blue phase. Blue phase is stable within about 4 degrees of the temperature range.
We propose the following phase diagram.

- on heating:

Cr $49.2^{\circ} \mathrm{C}$ SmG $66.5^{\circ} \mathrm{C} \quad \mathrm{SmI} \quad 68.9^{\circ} \mathrm{C} \quad \mathrm{SmC}$ $72.5^{\circ} \mathrm{C} \mathrm{SmA} 139.5^{\circ} \mathrm{C}$ Ch $143.2^{\circ} \mathrm{C}$ B $149.2^{\circ} \mathrm{C} \mathrm{I}$,

- on cooling:

I $144.5^{\circ} \mathrm{C}$ B $141.5^{\circ} \mathrm{C}$ Ch $137.7^{\circ} \mathrm{C}$ SmA $70.6{ }^{\circ} \mathrm{C}$ SmC $67.8^{\circ} \mathrm{C}$ SmI $64.7^{\circ} \mathrm{C}$ SmG $43.0^{\circ} \mathrm{C} \mathrm{Cr}$.

\section{References}

[1] H.J. Coles, M.N. Pivnenko, Nature 436, 997 (2005).

[2] J. Yamamoto, I. Nishiyama, M. Inoue, H. Yokoyama, Nature 437, 525 (2005).

[3] S. Meiboom, J.P. Sethna, W.P. Anderson, W.F. Brinkman, Phys. Rev. Lett. 46, 1216 (1981).

[4] O.D. Lavrentovich, M. Kleman, in: Chirality in Liquid Crystals, Vol. 5, Springer-Verlag, New York 2001.

[5] G. Pabian, M.Sc. Thesis, Cracow University of Technology, Kraków 2008. 